\title{
THE CHALLENGE OF DEFINING MEDICARE COVERAGE IN CANADA
}

\author{
J.C. Herbert Emery and Ronald Kneebone ${ }^{\dagger}$ \\ The School of Public Policy, University of Calgary
}

\section{SUMMARY}

There is a widespread impression among Canadians that their health-care system is universal, comprehensive and equitable. Given this impression, Canadians may be surprised to discover that, for instance, while annual physicals and receiving advice on dealing with cold symptoms are covered by the public plan, the costs of rehabilitation from a brain injury or stroke are not fully covered. While universal, the public plan is not comprehensive nor, arguably, is it equitable.

The Canada Health Act (CHA) uses the term "medically necessary" to define medical procedures and treatments to be paid for by the publicly-funded medicare system. In Canada's health-care system, the term has come to refer almost exclusively to those services provided by a physician, or provided within a hospital setting, by a physician or other staff. Services that a reasonable person might consider "necessary," but are provided outside those settings, are typically not covered.

In many ways the federally-legislated Canada Health Act has been culturally enshrined as a consecrated icon of national identity. But the legislation fails to clearly identify the line between necessary and unnecessary medical services. This has put provincial governments - who are responsible for medical-funding decisions - in the difficult position of having to make this decision, and they have resorted to drawing that line in sometimes surprising places. The line drawn between "necessary" and "unnecessary" medical treatments has been determined by the financial self-interest of medical stakeholders, by hospitals rationing global budgets, and by financially-constrained provincial governments. The result is a relatively narrow definition of medical necessity that undermines the equality goals the $\mathrm{CHA}$ is often claimed to uphold.

Health care is arguably the most important public-expenditure program in Canada. It is important for Canadians to understand clearly what services and levels of care this program provides so that they can prepare for, and possibly insure against, outcomes that are not covered. We do not argue it is easy to make this demarcation between what is and what is not covered by medicare. We do argue, however, that it is necessary to establish this line and to draw attention to its position.

\footnotetext{
$\dagger$ The authors wish to acknowledge the helpful comments of the anonymous referees.
} 


\section{INTRODUCTION}

Since the introduction of the Canada Health Act (CHA) in 1984, Canadian provinces have been obligated to provide citizens, through their tax systems, with health care defined to be "medically necessary." This is a highly popular, publicly funded program that is vigorously defended whenever changes are proposed or even contemplated. It is interesting, then, that very few Canadians fully understand what health services their governments choose to provide, what health services their governments are obligated to provide, and what health services their governments do not provide. In short, although they tend to strongly support it, Canadians do not know very much about their publicly funded system of health care.

This is not the fault of uninterested citizens. The problem, rather, is that the concept of "medical necessity" has not been well defined by federal or provincial legislation, beyond the very broad statement that it is a service provided either by a physician, or a service provided in a hospital by a physician or other medical professionals. The current definition of medical necessity results in the Canadian system of medicare being a partial health-insurance scheme in which full public coverage is available for doctors and hospitals, but only partial coverage is provided for other service categories. Most Canadians, for example, would be surprised to find that the public system does not pay the full and potentially catastrophic costs of rehabilitation services following a stroke or brain injury, but it does fully cover low-cost and regularly incurred services, such as annual physicals and receiving advice on dealing with cold symptoms. Is this a rational or desirable use of a public-insurance system? Were medicare designed as a comprehensive health-insurance scheme, it would be more akin to "medical catastrophe" insurance, with substantial deductibles or co-payments for predictable moderate expenses (for example: maternity care and outpatient prescription drugs) but ample coverage for unpredictable large losses (such as those related to brain injuries). ${ }^{l}$ The Kirby and Romanow health-care commissions recommended universal public payment/coverage for catastrophic drug costs over universal first-dollar payment - a recommendation consistent with medicare playing an insurance role. ${ }^{2}$ The provinces' reluctance to accept these recommendations suggests a resistance to the idea of defining medicare as insurance against catastrophic outcomes. ${ }^{3}$

To the extent that the definition of medical necessity determines what provincial governments will pay for in the medicare system, is the current 1984 CHA definition creating a result where health-care dollars meet the needs of the population? Would the population be better served by public funding directed by a different, or perhaps just clearer, definition of medical necessity?

These questions are closely related to one another and the answer to one requires answers to the other. This paper makes no attempt to answer these questions, or others posed above. Our goal is rather more modest: To identify the issues and highlight those considerations most important for resolving the conundrums that make answering these questions so challenging. We begin with asking a basic question: Why define what is medical necessity?

I On the other hand, Sherry Glied ("Health Insurance and Market Failure Since Arrow," Journal of Health Politics 26, 5 (October 2001)) notes that private insurers do not typically provide coverage to persons with chronic and predictable health conditions, making public coverage appropriate for addressing this "missing market."

2 See the glossary at the end of this paper for definitions of terms such as "universal first-dollar payment," and for brief descriptions of key commissions and reports relevant to our discussion of medical necessity.

3 This resistance has prompted analysts like Victor Fuchs ("Bismarck to Woodcock: The 'Irrational' Pursuit of National Health Insurance," Journal of Law and Economics 19, 2 (1976): 347-359) to describe systems like Canadian medicare as examples of an irrational use of an insurance function. 


\section{WHY DEFINE MEDICAL NECESSITY?}

The easy answer to this question is that the Canada Health Act of 1984 obligates provincial governments to pay for what it identifies as "medically necessary services." It would be good, then, to know what this means.

Cathy Charles and co-authors ${ }^{4}$ suggest that medical necessity has been understood to mean "what doctors and hospitals do." Colleen Flood, Mark Stabile and Carolyn Tuohy ${ }^{5}$ highlight that, in practice, "medical necessity" is defined as the product of provincial medical associations and government officials negotiating physician compensation. Neither of these definitions is very helpful for defining what medical services should or should not be covered by the public system. The lack of more concrete criteria for defining "medical necessity" is important because open-ended definitions of medical necessity are running up against increasingly tight provincial budget constraints. ${ }^{6}$ We therefore need to reconsider the definition of "medical necessity" if only to better define the limits for provincial governments' - and, so, provincial taxpayers' - financial commitments for universal, first-dollar, single-payer public coverage of health-care services.

If we start from the premise that provincial governments wish to continue keeping their financial commitment to health care limited to paying the costs of hospitals and doctors as required under the Canada Health Act, then the objective for the public payer is not to reform the system to an "ideal" health-care system, meeting all medical needs. Rather, it is to ensure that all acute-care-treatment needs associated with service delivery in a hospital and/or by a physician are met. The objective for the public payer would be to use a definition of "medical necessity" to control health expenditures, by eliminating the obligation to fund medically unnecessary physician services, services that do not need to be provided in an acute-carehospital setting, and to manage the adoption of new services arising through technical change. ${ }^{7}$ If a medically necessary service could be provided by a service provider other than a physician, and outside of a hospital setting, then more medically necessary care could be moved out of the medicare basket into the mixed-finance payment-service categories, with important consequences for the public payer's commitments, for the demand for service providers in the system, and for patients accessing care.

4 C. Charles, Jonathan Lomas, Mita Giacomini, Vandna Bhatia and Victoria Vincent "The Role of Medical Necessity in Canadian Health Policy: Four Meanings and ... a Funeral?" Milbank Quarterly 75, 3 (1997): 365-394. Also see: Robert Evans, "Canada: The Real Issues," in The Politics of Health Care Reform: Lessons from the Past, Prospects for the Future, ed. James A. Morone and Gary S. Belkin (Durham, NC: Duke University Press, 1994). Evans points out that the test of medical necessity of a service has been "that a properly licensed physician was willing to provide it and a patient to accept it."

5 Coleen M. Flood, Mark B. Stabile and Carolyn H. Tuohy, Defining the Medicare "Basket" (Ottawa: Canadian Health Services Research Foundation, 2008).

6 In most provinces, health-care costs consume over 40 per cent of provincial revenues. Livio Di Matteo and Rosanna Di Matteo ("The Fiscal Sustainability of Alberta's Public Health Care System," School of Public Policy, University of Calgary, SPP Research Papers 2, 2 (2009)) estimate that, by 2030, health spending may consume upwards of 80 per cent of provincial revenues.

7 Evans ("Canada: The Real Issues" ) claims that many services provided by physicians, or during stays in hospital, have no demonstrable health benefit. In the absence of a health benefit from the service, the service is not medically necessary and could be de-insured (i.e., removed from medicare coverage). 
In addition to limiting governments' (and taxpayers') exposure to growing demands for health services, it is desirable to define what will be provided by medicare (that is, to define what is medically necessary) so as to inform citizens about their obligations in self-insuring against catastrophic outcomes and long-term care needs. For example, a 2012 report by the Canadian Life and Health Insurance Association on long-term care identified that "many Canadians continue to have the mistaken belief that all of their long-term care needs will be met by government." ${ }^{8}$ This mistaken belief and the unfortunate consequences that result are, we would argue, due to a failure to make clear to Canadians what medical necessity means and what implications this definition has for them in having their health-care needs met.

\section{MEDICAL NECESSITY CURRENTLY DEFINED}

To develop an understanding of how we might address the role of medical necessity in defining the medicare "basket" we next review how the boundary between medicare and non-medicare services is presently set and how it was determined.

A background paper prepared for the Commission on the Future of Health Care in Canada popularly known as the Romanow Commission - describes medical necessity as the criterion for determining the division of services between the first-dollar, single-payer public coverage under medicare and the mixed-payment arrangement:

"When a service provided to a patient is medically necessary, it is fully funded by the government and delivered based on the patient's need, not their ability to pay. If a service is deemed unnecessary, however, patients must pay for it directly. The idea is to have need, not want, dictate what the healthcare system provides."

In contrast to the Romanow Commission's view, Canadian courts have ruled that medicare is not based on broadly defined health-care needs but instead it is based on a "sectoral" consideration of medical necessity. ${ }^{10}$ In ruling on the Auton case, the Supreme Court of Canada, in a unanimous decision, remarked that Canadian medicare "is, by its very terms, a partial health plan and its purpose is not to meet all medical needs." 11 Thus while it may be correct in saying that the premise of Canadian medicare is about meeting vital needs rather than satisfying consumption desires, the court recognizes that medical necessity defines medicare as coverage only for acute-care medical treatment and not more broadly defined health needs.

8 Canadian Life and Health Insurance Association Inc., "Improving the Accessibility, Quality and Sustainability of Long-Term Care in Canada," June 2012.

9 Commission on the Future of Health Care in Canada, "Medical Necessity: What is it, and who decides?" Issue/Survey Paper, July 2002: 3.

10 For an excellent discussion of the sectoral definition and alternative finance structures for public payment of health services, see: Carolyn Hughes Tuohy, Colleen Flood and Mark Stabile "How Does Private Finance Affect Public Health Care Systems? Marshaling the Evidence from OECD Nations," Journal of Health Politics, Policy and Law 29, 3 (2004): 359-396.

11 Auton (Guardian ad litem of) v. British Columbia (Attorney General), 2004 SCC 78 (CanLII), [2004] 3 SCR 657, http://canlii.ca/t/1j5fs. 


\section{Floors and Ceilings}

The Supreme Court's interpretation of the meaning of medical necessity stems from the legislation from which Canada's provincial health-care systems have evolved. Public payment for services provided in hospitals was introduced with the 1957 Hospital Insurance and Diagnostic Services Act, and public payment for physician services was introduced with the 1966 Medical Care Act. These acts defined the conditions under which the federal government shared the costs of provincial hospital programs, and the framework of provincial programs paying for physician services. ${ }^{12}$ Charles et al..$^{13}$ emphasize that, as there was no preclusion of private payment for medicare services, these legislative acts used the concept of "medical necessity" to establish the public payer as the first payer for core medical services, and to define a floor level of public coverage for medical needs.

Public payment for physician services and hospitals changed from a first-payer first-dollar coverage to single-payer first-dollar coverage under the 1984 Canada Health Act. Under the $\mathrm{CHA}$, to meet the conditions for full transfer payments from the federal government, the provinces were required to finance all medically necessary physician and hospital services such that there would exist no financial barriers to access for these services. Under the CHA, the federal government could levy a one-dollar penalty on a province's block funding for every one dollar of extra charges to patients, whatever the source of these extra charges. ${ }^{14}$ As Charles et al. ${ }^{15}$ note, the preclusion of private payment for medicare services under the CHA invoked "medical necessity" to define a ceiling for payment for medically necessary services by the single public payer, and so, introduced a significant change in the understanding of medical necessity from what was understood earlier. The ceiling, however, was not clearly defined in terms of services provided but, rather, was understood to be defined as "the maximum insured benefits that the provinces can afford."

\section{Delisting}

The federally legislated definitions of medical necessity leave discretion for how provinces define what hospital and physician services are medically necessary or medically required, and what levels of services are medically necessary. Provinces can "delist" those services provided by physicians that government determines are not "medically necessary" or are not necessary

12 Keith Banting and Robin Boadway ("Defining the Sharing Community: The Federal Role in Health Care," in Money, Politics and Health Care: Reconstructing the Federal-Provincial Partnership, ed. Harvey Lazar and France StHilaire (Montreal: Institute for Research on Public Policy, 2004): Chapter 1) identify the four conditions for federal cost-sharing as being: universal coverage on uniform terms and conditions; portability of benefits from province to province; comprehensive payment coverage for all medically necessary services; and a publicly administered nonprofit program. The 1984 Canada Health Act introduced a fifth condition of accessibility to medicare by indirectly banning extra billing by physicians and user fees for medicare services.

13 Charles et al., "The Role of Medical Necessity."

14 For a detailed discussion of regulations under the CHA, see: Gerard Boychuk, "The Changing Political and Economic Environment of Health Care," in The Fiscal Sustainability of Health Care in Canada: Romanow Papers, Volume 1, ed. Gregory P. Marchildon, Tom McIntosh, and Pierre-Gerlier Forest (Toronto: University of Toronto Press, 2004) Chapter 9. 
to provide in a hospital setting. Provinces can also define a level or frequency of service as medically necessary and define additional services, or higher service levels, as enhanced services that can be paid for by private sources. ${ }^{16}$ It is not the case that other categories of service are not medically necessary, only that the public payers have defined the limits of their hard commitment for first-dollar, universal, single-payer coverage to doctors and hospitals. ${ }^{17}$ Delisting does not necessarily eliminate the availability of the "medically unnecessary" service; it instead moves the service into the mixed-payment category of services.

\section{Provincial Differences}

Outside of the medicare spending categories of doctors and hospitals, decisions to provide public payment vary across provinces. Cross-province variations reflect the fact that it provincial medical associations and provincial government officials negotiating physician compensation that largely determine definitions of medical necessity.$^{18}$ Moreover, the list of insured services, and the generosity of coverage for those services, evolves over time and is often impacted by economic conditions and the budget pressures of provincial governments. As these pressures differ by province and over time, it is not surprising to find that the definition of medical necessity varies over these dimensions.

Generally, public funds are not used to cover the costs of non-medicare services on a universal, first-dollar basis. ${ }^{19}$ As part of a mixed-payment arrangement, public payment for dental care, eye care and drugs, is often targeted at low-income, and/or elderly, members of the population and used to cover part of the total cost of a service. Whether or not, and to what extent, a given province funds a given non-medicare service depends on considerations such as whether the service in question will impact the medicare-financed health-care system (e.g., in-vitro fertilizations, which increase multiple births, thus raising costs in the public system); whether other provinces have chosen to pay for the service; and generally, the strength of political pressure to fund the service (e.g., expensive cancer drugs).

16 For example, for stays in hospital, the CHA accommodates patients paying privately for semi-private room accommodation and other "comforts." The CHA only requires the public payer to cover accommodation and meals at "standard ward levels" (see Boychuk, "The Changing Political," 12). Alan Davidson ("Under the Radar: Stealth Development of Two-Tier Healthcare in Canada," Healthcare Policy/Politiques de Santé 2, 1 (2006): 25-33) discusses British Columbia's limits on the frequency of routine medical examinations and laboratory tests.

17 Flood et al., Defining the Medicare "Basket." Of course, the interpretation of non-medicare services as being not medically necessary is inconsistent with other federal government definitions of medical necessity. Many services and products deemed medically unnecessary in provincial medical schemes are deemed medically necessary under Canadian tax laws, enabling patients to be partially reimbursed via the tax system. As out-of-pocket health-care payments increase with the rise of non-medicare health-care expenditures, Canadians will have greater awareness of this dual definition of medical necessity.

18 For a discussion see: Flood et al., Defining the Medicare "Basket."

19 Vaccination programs, counseling/mental health services, physical therapy, optometry, abortion, and laboratory services are at least partially funded in some regions, although they are commonly delivered by non-physicians outside of hospital settings. 


\section{Pressures on the Status Quo}

Budget considerations of provincial governments, technical changes in health care, and changes in health needs associated with an aging population are bringing attention to the distinction between necessary acute-care medical treatment and the broader definition of health-care services. Financial and demographic pressures are causing more health-care needs associated with aging and chronic diseases to fall outside the CHA definition of necessary acute-care medical treatment.

These pressures are relatively new. Until recently, the public finance commitment to expenditures on physician services and hospitals defined under federal legislation, such as the 1984 CHA, was not problematic for Canadians. This was so for at least two reasons. First, the correlation of medicare-paid services and medically necessary services were higher in the 1960s and 1970s as a younger population resulted in a prominence of acute over chronic care. An aging population with chronic conditions, combined with new technologies and drug treatments, have shifted focus - and costs - toward health-care treatments that can be provided outside of hospital settings or that have not been added to the medicare roster of insured services. ${ }^{20}$ Second, prior to the deficit crisis of the 1990s, governments paid generously for health-care services outside of the hospital and physician boundaries of the CHA by choice/discretion, often using borrowed funds. Charles, et al. ${ }^{21}$ note that only with rising debt and debt-servicing costs and the consequent squeeze on provincial budgets did Canadians become aware that comprehensive coverage for doctors and hospitals differed from comprehensive health-care coverage.

These demographic and financial considerations are putting pressure on provincial governments to either publicly fund a smaller portion of the growing health-care needs of Canadians, raise taxes (or crowd out other government spending) to maintain coverage of those growing needs, or to rethink the boundaries of publicly funded health care.

\section{RETHINKING THE BOUNDARIES}

If the current definition and concepts of medical necessity are unaffordable or too limited, how should we think about coming up with a preferred definition? This question of what defines a health service as medically necessary has received considerable attention from the federal and provincial governments as well as from some of Canada's leading health-policy scholars over the past 25 years..$^{22}$ What are the key points of discussion?

20 As late as the 1990s, Evans (“Canada: The Real Issues") suggested that, other than dental services, the expenditures on non-medicare services were relatively small amounts. However, the Conference Board of Canada ("Understanding Health Care Cost Drivers and Escalators," Report, March 2004) suggests that expenditures on pharmaceutical drugs in Canada by provincial and federal governments are forecast to equal expenditures on physician services by 2020 .

21 Charles et al., "The Role of Medical Necessity."

22 Members of the Centre for Health Economics and Policy Analysis (CHEPA) at McMaster University, Colleen Flood and colleagues at the University of Toronto, Raisa Deber and colleagues at the University of Toronto, and the University of British Columbia's Centre for Health Services and Policy Research (CHSPR) have all had large projects in the 2000s addressing this issue from a comprehensive set of perspectives. Flood et al., (Defining the Medicare "Basket") identify at least five recent federal and provincial commissions on health care that have considered issues around defining the medicare commitments of governments in Canada. Finally, J. Schreyögg et al., ("Defining the 'Health Benefit Basket' in Nine European Countries: Evidence from the European Union Health BASKET Project," The European Journal of Health Economics [Suppl. 1] 6 (2005): 2-10) describe a project for Europe that examines how core services for public payment differ in nine EU countries. 


\section{A Broad or Narrow Definition?}

Jeremiah Hurley and co-authors ${ }^{23}$ present two opposing perspectives on how medical necessity could be defined. First, if the word "medical" is taken literally, then medical necessity defines who can determine necessity and restricts consideration to conditions with a formal medical diagnosis. Alternatively, if health, rather than the absence of illness, becomes the objective of care, the inclusion of a broader range of conditions and treatments is justified.

In an attempt to add rigour to our thinking on this issue, James Sabin and Norman Daniels ${ }^{24}$ identify three models for defining "medical necessity." First, the "normal function" model defines "the central purpose of health care" as "to maintain, restore, or compensate for the restricted opportunity and loss of function caused by disease and disability." The "capability model" defines the role of health care as giving "people equal personal capabilities, or at least giv[ing] priority to those whose diminished capability (whatever the cause) puts them at a relative disadvantage." Finally, the "welfare model" defines the purpose of health care as providing treatments that enhance abilities and happiness, and alleviate suffering. ${ }^{25}$

It is not long before thinking along these lines causes anxiety in governments seeking to balance budgets and constrain costs. For this reason, proposals to fund expansions to the boundaries of medicare - to cover, say, drugs and homecare - do not typically involve funding them on the same single-payer basis as payments to doctors and hospitals. Typically the proposals are not even to fund these services on a first-dollar basis.

Michael Bliss ${ }^{26}$ and Raisa Deber ${ }^{27}$ both argue that Canadian governments are wary of expanding into universal drug coverage because of history's lessons about the problems of cost escalation. The 2002 Romanow Commission and the 2002 Kirby Commission both considered how public payment for outpatient drug costs could be improved and whether outpatient drug costs should be included as part of medicare. Both commissions proposed forms of "universal catastrophic" drug coverage. The parameters of the proposed programs differed, but both commissions proposed that the public payer would cover costs above an "affordability" threshold for individuals. The reason that the commissions were not proposing universal, single-payer, first-dollar coverage was the concern that provincial and federal governments could not afford to take on coverage of drugs on those terms. This concern was rooted in the

23 Jeremiah Hurley et al., "Medical necessity, benefit and resource allocation in health care," Journal Health Services Research and Policy 2, 4 (October 1997): 223-229.

24 J. Sabin and N. Daniels, "Determining 'medical necessity' in mental health practice," The Hastings Center Report 24, 6 (1994): 5-13.

25 Were this not enough, even the legitimacy of health-care needs has been questioned. Anthony Culyer and Adam Wagstaff ("Equity and equality in health and health care," Journal of Health Economics 12 (1993): 431-457) suggest that, if need is simply defined as what is required for fulfillment or maintenance of health, then

"...it is hard to see why someone who is sick can sensibly be said to need health care, irrespective of the latter's ability to improve the person's health. A person cannot surely be said to need health care if no technology is available to improve their health or prevent its avoidable deterioration.

They may need medical research, they may need comfort, and they may, most fundamentally of all, need health, but they surely do not need health care." (p. 444)

26

Michael Bliss, "Critical Condition: A Historian's Prognosis on Canada's Aging Healthcare System," C.D. Howe Institute, Benefactors Lecture, 2010.

27 R. Deber, "Canada," in Cost Containment and Efficiency in National Health Systems: A Global Comparison, ed. J. Rapoport, P. Jacobs and E. Jonsson (Weinheim, Germany: Wiley-VCH Verlag GmbH \& Co. KGaA, 2009). 
rapid growth of drug expenditures over the previous decade and concern over the open-ended commitment for a class of health interventions where innovation effort seemed to be producing an endless stream of new drugs at higher and higher prices.

Åke Blomquist ${ }^{28}$ raises the issue that it is getting harder to rationalize the logic for how the public payer covers things such as drug costs and homecare asymmetrically from how it pays for physician services. Many outpatient prescription drugs would fit the criteria for being medically necessary and, in other developed countries, outpatient drug costs are covered on the same terms as physicians and hospitals. For example, unlike the case of doctors and hospitals, medical necessity in the context of public payment of outpatient pharmaceuticals has been balanced against budget considerations and concerns about health disparities, and a potential redistributive role of public spending is not considered to be of central importance..$^{29}$

But if one constrains the definition of medical necessity to what is currently covered by medicare, we are put in the difficult position of justifying current coverage. To suggest that annual medical check-ups are medically necessary while essential drugs like insulin are not (and so are not funded on a first-dollar basis in many provinces) flies in the face of what most Canadians would deem appropriate and seems inconsistent with the premise that medicare is about meeting vital health needs. ${ }^{30}$ Similarly, the different treatment of doctors services and hospital-care settings from other categories of health services seems at odds with the perceived "equality purpose" of Canadian medicare. Sherry Glied ${ }^{31}$ has argued that if Canadians are prepared to tolerate inequalities like this outside of the medicare basket, then the logic of continuing with single-payer coverage for doctors and hospitals based on equality goals must be weakened. Maintaining a narrow definition of medical necessity therefore undermines the equality goals it is often claimed to uphold.

Existing definitions of what is medically necessary may also be flawed due to a failure to recognize how public coverage might directly or indirectly influence acute-care costs. Thus, long-term care or home care, while not deemed to be medically necessary, have an obvious and large impact on the acute-care medical treatment system as unmet long-term care needs drift into the acute-care setting. Failing to appreciate this connection gives rise to situations like that recently discussed by Steven Lewis and Terrence Sullivan ${ }^{32}$ who note:

"When a frail elderly person walks into an emergency room with an impending heart attack, the system is instantly primed to spend tens of thousands of dollars for tests, surgery and a hospital stay. However, that is often the same person who languished at home, mildly depressed, isolated, physically inactive and malnourished - someone for whom the system refused to spend a few hundred dollars a month on home care to prevent the catastrophe that ended up in the emergency room and the operating room."

28 Åke Blomquist, "Reforming Canadian Medicare: Can an Icon be Redesigned?" in Canadian Policy Debates and Case Studies in Honour of David Laidler, ed. Robert Leeson (New York: Palgrave Macmillan, 2010).

29 Malcolm Taylor (Health Insurance and Canadian Public Policy: The Seven Decisions that Created the Canadian Health Insurance System (Montreal: McGill-Queen's University Press, 1978)) notes that provinces in the 1960s were hesitant to take on payment of physician services for the same reasons. Federal cost sharing overcame some of their concerns.

30 This example comes from Flood et al., Defining the Medicare "Basket."

31 Sherry Glied, "Universal Public Health Insurance and Private Coverage: Externalities in Health Care Consumption," Canadian Public Policy 34, 3 (2008): 345-357.

32 Steven Lewis and Terrance Sullivan "How to Bend the Cost Curve in Health Care," IRPP Insight 1, May 2013: 6. 


\section{Foxes in the Henhouse?}

Concern over cost control is one reason why it may be a challenge to expand the definition of medical necessity. Another is based in self-interest. For example, Charles et al. are pessimistic that it is possible to achieve consensus on the meaning of medical necessity because its meanings are malleable and contingent on stakeholder policy and ideological ends. ${ }^{33}$ Similarly, Raisa Deber and Brenda Gamble ${ }^{34}$ suggest that a reason for this is that "the vision of many policy elites remains heavily linked to the current system of guaranteed public funding only for acute care in hospitals or by physicians. Successful reform will need to address, rather than assume, a broader view of healthcare."

If this view is correct - that self-interest is restricting discussions of the concept of medical necessity to those that are currently defined under the 1984 Canada Health Act - then it becomes a challenge to defend why services defined as "medically necessary" should only be those provided by physicians, or provided in hospitals by physicians and other health professionals.

Self-interest exerts itself not only by protecting the status quo, but also by promoting approaches to reconsidering the status quo. Thus, Bliss ${ }^{35}$ argues that where the maxim of the mid-20th century was that health care was too important to be left in the hands of doctors, the tide has turned against the interests and stakeholders that had promoted that view - namely, politicians, bureaucrats and economists. These latter groups, he alleges, attempted to control costs and suppress patient demand with neither the cooperation nor the approval of the professionals most qualified to practice good medicine. Governments and economists, suggests Bliss:

" ... might remember that their mandate is limited to finding ways to pay for the very high levels of healthcare that modern medicine has made possible and that the Canadian people clearly expect to receive. Diagnosing and treating our sickness is mainly the job of doctors, interacting with patients' perceptions of medical need. The notion that physicians' economic self-interest - under, say, fee-for-service payment - constantly overrides their professionalism, idealism, and "real" patient needs, and other considerations also might reflect the prejudices, self-interest, and penchant for intellectual reductionism of groups that are contesting for power and influence within the system ... The need for groups to work more smoothly and harmoniously, with more trust and mutual respect, within the healthcare system seems palpable."36

33 Charles et al., "The Role of Medical Necessity." See also: Alan Shiell and Gavin Mooney ("A Framework for Determining the Extent of Public Financing of Programs and Services," Commission on the Future of Health Care in Canada, Discussion Paper No. 6, 2002) who suggest there are no ready-made technical fixes and there is no point in seeking a completely technical, evidence-based approach.

34 R. Deber and B. Gamble, "What's In, What's Out: Stakeholders' Views About the Boundaries of Medicare," Longwoods Review 2, 3 (2004): 2-10.

35 Bliss, "Critical Condition."

36 ibid, 24. 
Bliss's strong comments about the self-interest and lack of objectivity of economists seeking to influence the allocation of health-care resources cannot be easily dismissed. Many of the economists and health-policy advisors calling for a greater role of their skills, knowledge and tools in managing the health-care system have been providing advice to government that has led to increases in funding for their own research along with increases in their own incomes as they are hired to take on the work or advise government in a consulting role. In the role of advisor/consultant, what guidelines and standards are in place to ensure that economists and health-services researchers are not acting in their own self-interest and inducing demand for their own services?

\section{A Technical Definition of Medical Necessity?}

If it is difficult to defend the list of health-care services that are, and are not, considered to be medically necessary, and if one is concerned that those currently making these choices governments and economists interested in cost control and medical professionals interested in defending their place to freely allocate resources as they see fit - then an obvious avenue is to rely on more-technical definitions.

On the surface, it would seem that what is a "medical necessity" would largely have a technical determination. To quote Tommy Douglas, "no boy should have to depend either for his leg or his life upon the ability of his parents to raise enough money to bring a first-class surgeon to his bedside." But it is not that easy.

Defining medical necessity as contingent on the existence of scientific evidence of service/product effectiveness provides a useful criterion for delisting ineffective or costineffective services, offers an opportunity to contain costs, and allows for additions of new services. Clinical evidence that the service or product produces health benefits should direct clinical decisions to eliminate unnecessary services and, hence, unnecessary public expenditures. As Deber ${ }^{38}$ assesses, "Recognizing that unneeded care may represent cost without benefit, or even cost to cause harm, providers and payers have moved towards an increased use of such approaches as evidence-based medicine, technology assessment and various forms of clinical guidelines." Bliss ${ }^{39}$ describes the appeal of the perspective for governments seeking to control public health-care expenditures:

"Not surprisingly, cost controllers in government were attracted to the ideas of those healthcare 'reformers,' some within the care-giving professions, who believed that the 'system' was heavily and unnecessarily marbled with overtreatment, conflict of interest on the part of providers, and misplaced emphasis on high-tech, curative procedures. Perhaps Canada could do more with fewer physicians, hospital beds, laboratory tests, intensive-care units, and heroic surgical interventions."

\footnotetext{
37 Quotation taken from "Making Medicare: The History of Health Care in Canada, 1914-2007," Exhibit, Canadian Museum of Civilization (http://www.civilization.ca/cmc/exhibitions/hist/medicare/medic-3g03e.shtml).

38 Deber, "Canada."

39 Bliss, "Critical Condition," 10.
} 
Despite the promise of evidence-based definitions for appropriateness and effectiveness, it is not clear that decision-makers have been basing funding decisions on scientific evidence. Charles et al $^{40}$ assess that delisting on the grounds that services are not medically necessary has not led to substantial cost savings in public systems. This may reflect that application of medical necessity has not been sufficiently rigorous or that governments are not politically strong enough to withstand the public's response to change. Or it could reflect that there are few savings to achieve in this way. There is also the problem that the scientific data on efficacy or effectiveness or costs of interventions are of insufficient quality or availability to implement effectiveness-evaluation on a sufficient scale to see many benefits. ${ }^{4 l}$ The study of efficacy is therefore expensive and would require a substantial commitment of resources beyond what has been made.

At the heart of the matter is the fact that health issues are many and varied, making technical definitions of what is medically necessary difficult; they are not all categorical cases of a service or procedure being necessary or not, as most services and interventions will be appropriate for some patients in some situations. It is not as easy as Tommy Douglas may have thought.

\section{Doctors Know Best?}

The uniqueness of every health encounter may make a one-size-fits-all technical definition of medical necessity difficult. Services and/or products are not categorically "necessary" or "unnecessary." Thus, any approach to defining medically necessary services other than by the clinical judgment of a physician treating a patient may be infeasible to implement. What is more, in Canada we have no way of determining what a physician did to a patient, since we only know that the physician billed for a contact with the patient. Whatever restrictions might be placed on which procedures are considered medically necessary, and so billable to the public payer, clinicians can always find ways around those restrictions.

The notion that "doctors know best" is what lies behind the Canadian medicare approach that holds that the definition of medical necessity should be based upon who provides a service and where it is delivered, rather than what the service is. Defining medical necessity as "what physicians and hospitals do" reflects a reliance on, or perhaps trust in, the authority of the medical profession to determine necessary care.

40 Charles et al., "The Role of Medical Necessity."

41 The Office of Technology Assessment estimates that efficacy has been shown by randomized clinical trials for fewer than 20 per cent of medical practices. See Donald M. Berwick, "Health Services Research and Quality of Care: Assignments for the 1990s," Medical Care 27, 8 (August 1989): 763-771. 
Clinical discretion of physicians is problematic in Canada and elsewhere since it offers no mechanism for cost control, nor is there clear accountability for decisions made and the link to evidence of effectiveness. Clinicians can provide any service they believe necessary (and generate limitless revenue) with no obligation to demonstrate benefit. Clinical discretion results in variations in treatments provided among patients with similar conditions but treated by different providers. Berwick ${ }^{42}$ summarizes that:

"It was more comfortable when the health care system was a black box with trusted physicians inside doing, payers assumed, the right thing. Health care is embarrassed to realize how little of what it does is of known, scientifically proven efficacy; perhaps less than $20 \%$ of what physicians do every day has been shown to be of clear value in well-designed clinical studies. We are embarrassed to learn that rates of surgical procedures, medication, and testing vary by as much as an order of magnitude from city to city, hospital to hospital, and even doctor to doctor."

Similarly, Lomas ${ }^{43}$ referring to the claim that as much as 20 per cent of health care was "inappropriate," with no impact on effective care, notes that:

“... the exponentially increasing possibilities in health care - technologically and as we expand into broad concepts of health promotion - are coming into conflict with a limited fiscal capability. This has led to a decreased tolerance for the provision of marginally useful or, more importantly, useless health care, and an increased need to identify and remove such 'surplus' activity to free up the funds for exciting new possibilities."

\section{Practice Guidelines?}

In the absence of scientific evidence on efficacy, and given concerns over the "doctors know best" solution, some physicians and health experts have proposed appropriateness guidelines for providing health care. Like any compromise solution, the use of appropriateness guidelines has its critics. Berwick, ${ }^{44}$ for example, does not see these sorts of guidelines as substitutes for scientific evidence and fears they may only result in the entrenchment of ineffective habits and practices. Charles et al. ${ }^{45}$ note that practice guidelines as a policy tool to ration availability of publicly insured services on a population level limits the flexibility of physicians to make clinical decisions to reflect a patient's unique circumstances. In addition, Lomas ${ }^{46}$ notes that the more strict the application of guidelines for patient treatment, the greater the need for an appeals process for patients and physicians who disagree with the guideline for a particular patient.

\footnotetext{
42 Berwick, "Health Services Research," 764.

43 J. Lomas, "Editorial: Quality Assurance and Effectiveness in Health Care: An Overview," Quality Assurance in Health Care 2, 1 (1990): 5-12.

44 Berwick, "Health Services Research."

45 Charles et al., "The Role of Medical Necessity."

${ }^{46}$ Lomas, "Editorial."
} 


\section{Back to the Future?}

Given the generally held view that it is fruitless to develop a technical definition of what is and what is not medically necessary, and the likelihood that physicians will need to be relied upon to make this assessment, leaving little scope for identifying cost-effectiveness, researchers have returned to previous considerations of floors and ceilings as a way of controlling demands for ever more public funding. Thus, Flood et al. ${ }^{47}$ advocate that medical necessity be used to establish a "floor level" of coverage by first-dollar, universal public payment, beyond which private payment could be used for "enhanced" levels of service. This is currently the case with respect to hospital stays and, as noted earlier, according to Charles et al., ${ }^{48}$ this was the intent behind the definition of medical necessity prior to 1984 .

The "floor" definition effectively alters the public single-payer model to public first-payer, mixed-finance system, without any obvious violation of the Canada Health Act. If we determine medically necessary levels of public payment on a broader set of services than doctors and hospitals, then we need to open up the dialogue to a discussion of what, and how much, of the costs of health-care interventions the public payer should cover, and how much should be left for private payment.

Building on the idea of medicare providing a floor of coverage, Flood et al.$^{49}$ propose that medical necessity could be defined so as to determine a level of service that will be 100-percent publicly funded, and beyond which non-essential enhancements could be offered in return for private payment. Non-essential enhancements could be higher-quality prosthetic joints, diagnostic imaging for conditions beyond the range that is cost-effective, or access to services faster than the time limit offered by the public system. The intriguing part of this proposal is that while it superficially maintains a "single-payer, universal" core of publicly funded services, it amounts to having a two-tier system of health care, much like that in Australia, where private health insurance largely covers the "gaps" between publicly funded service levels and desired service levels of individual patients.

These authors do not discuss how their proposed framework for defining the core medicare basket fits with the existing CHA legislation. The proposal to allow private payment for faster access to services than that offered by the public system as an "enhanced service" would seem to be at odds with Roy Romanow's interpretation of the purpose of medicare and the values of Canadians:

"It has been suggested to me by some that if there is a growing tension between the principles of our health care system and what is happening on the ground, the answer is obvious. Dilute or ditch the principles. Scrap any notion of national standards and values. Forget about equal access. Let people buy their way openly to the front of the line. Make health care a business. Stop treating it as a public service, available equally to all. But the consensus view of Canadians on this is clear. No! Not now, not ever. Canadians view Medicare as a moral enterprise, not a business venture." 50

\footnotetext{
47 Flood et al., Defining the Medicare "Basket."

48 Charles et al., "The Role of Medical Necessity."

49 Flood et al., Defining the Medicare "Basket," 4-5.

50 Roy Romanow, "Building on Values: The Future of Health Care in Canada, Commission on the Future of Health Care in Canada, Final Report ," November 2002: xx.
} 
Alan Davidson ${ }^{51}$ describes approaches like the Flood et al.$^{52}$ proposal as nothing more than "boundary shifting" for public payment that has resulted in the evolution of a two-tier healthcare system. Davidson is not so much concerned about the "de-insuring" of services of "dubious clinical merit, such as neo-natal circumcision," but is more concerned about the decisions of the provinces to "de-insure" or "place limits" on the frequency of routine medical examinations, and to impose limits on the routine ordering of laboratory tests and imaging. Davidson argues that these shifts in the boundaries and limits of public coverage created "a small niche market for privately financed health examinations, including privately financed diagnostic imaging services for the worried well." ${ }^{53}$ Davidson raises the concern that with the case of wait times for elective procedures, "privately financed diagnostic and treatment clinics exist precisely to provide services more expeditiously than is justified by the evidence-based guidelines informing the publicly funded system." Once this private market is in place, it creates a clearly two-tiered system. ${ }^{54}$

\section{Sieves and Filters}

Even if the boundaries of the medicare basket of health services cannot feasibly be determined on technical considerations of medical necessity alone, Shiell and Moone ${ }^{55}$ suggest that defining medical necessity can still be worthwhile as part of a broader exercise of priority-setting for public payment of health-care services that is explicit, more structured and more consistent with broad social objectives. Supporting this view is Werner Brouwer and Frans Rutten ${ }^{56}$ who argue that priority-setting for public payment of health-care services will always be subject to the political climate, including the influence of the media and lobby groups, but having a transparent and common understanding of the meaning of medical necessity for the purpose of limiting taxsupported, as opposed to private payment, will support rational policy-making.

Charles et al. ${ }^{57}$ describe multi-level filters that build off of definitions of medical necessity that can be applied to determine core health-care services for public payment. The word usage differs but typically the first filter is the efficacy/effectiveness of an intervention or service as demonstrated by scientific evidence. The second filter is then something like "appropriateness" or "ethics," and the third level of filter is "affordability" or "economic" considerations. For example, Flood et al..$^{58}$ propose criteria for Canada to define the medicare basket as follows: "Judgements about services and treatments to be included in the publicly funded basket should be based on medical need, evidence of efficacy, and costs. All decisions should be guided

51 Alan Davidson, "Under the Radar: Stealth Development of Two-Tier Healthcare in Canada," Healthcare Policy/Politiques de Santé 2, 1 (July 2006): 25-33.

52 Flood et al., Defining the Medicare "Basket."

53 Davidson, "Under the Radar," 28.

54 Davidson's concern with this situation is that he believes that the potential market for "expedited services" is too small to finance private diagnosis and treatment, hence it requires the "unused capacity" funded by other sources such as workers' compensation boards.

55 Shiell and Mooney, "A Framework for Determining."

56 W. Brouwer and F. Rutten, "The Netherlands," in Cost Containment and Efficiency in National Health Systems: A Global Comparison, ed. John Rapoport, Philip Jacobs and Egon Jonsson (Weinheim, Germany: Wiley-VCH Verlag GmbH \& Co. KGaA, 2010): Chapter 6.

57 Charles et al., "The Role of Medical Necessity."

58 Flood et al., Defining the Medicare "Basket." 
primarily on these factors." They also discuss other factors that enter the decision, such as the "fiscal externalities" of using private finance for a service and the need to service small or marginalized populations.

Brouwer and Rutten ${ }^{59}$ describe a "four-sieve funnel" proposed for the Netherlands to determine if a health-care intervention should be included in that country's basic public health-benefits package. This "Dunning Funnel" is a useful structure to consider how multi-level criteria might aid in determining the content of the medicare baskets in Canadian provinces. First, the health problem under consideration must make an intervention necessary. Second, the intervention must be "effective" in the sense that it can be expected to lead to a health improvement. Third, efficiency considerations require that the intervention be "good value for money," meaning that the intervention achieves health improvements at a reasonable cost. Fourth, does the intervention require public payment or could it be left to the individual? For Canada, among the medicare services defined by the $1984 \mathrm{CHA}$, only the fourth sieve is potentially incompatible with the existing legislation as criteria for "medical necessity."

\section{Cost-Effectiveness and Opportunity Cost}

Flood et al.$^{60}$ see technical considerations of effectiveness as important. But in the context of a public payer who, it is assumed, cannot afford to cover every medical need, they argue that opportunity-cost considerations must guide whether the service is in the medicare singlepublic-payer basket versus the mixed-payment sector. As discussed above, this economic consideration is typically the third consideration proposed for defining core services from the set of medically necessary services defined by effectiveness.

These authors propose that the "medicare basket" of services funded universally by a single public payer should be "based on scientific evidence of efficacy, cost-benefit analysis and public values." They further argue that the scope of public coverage should be based on the benefit of the service to the patient, and not who provides the service or where it is provided. The authors interpret the consideration of cost-effectiveness of treatments as expanding notions of medical necessity as something akin to "medically reasonable," by bringing in explicit consideration of the services' budget impact and the relative costs and benefits. Combining these criteria with a maintained assumption that public-payer budget limitations make funding of all medically necessary services impractical, the authors propose the use of "medical opportunity cost" as a criterion for determining which medically necessary services should be included in the medicare basket. To the extent that funding a medical service ties up funding that could have been put towards other services, the authors propose that the comparative contribution to health foregone by excluding a given service from the basket be used to prioritize services for universal first-dollar public payment.

\footnotetext{
59 Brouwer and Rutten, "The Netherlands," 149-50.

${ }^{60}$ Flood et al., Defining the Medicare "Basket."
} 
Cost-effectiveness, value for money, or other terms for the opportunity cost of a health intervention are different considerations than "does the intervention result in a health benefit?"

Now, what matters is the relative cost of achieving that health outcome. Interventions that yield a small benefit at low cost may be seen as more preferable targets for public payment than large health-benefit but expensive interventions, on a "value for money" basis. Cost comparisons of alternative interventions for a given medical condition represent a lesscontentious application of this perspective, since it is really identifying ways to reduce the costs of meeting a given need. ${ }^{61}$ On a system-wide level, however, comparing interventions across different medical conditions is a more contentious exercise, since the objective is more clearly seen as a resource reallocation within the health-care budget across the members of the population. ${ }^{62}$

Cost-effectiveness has primarily been applied to decisions to fund new technologies and new drugs, but has not been as widely applied to the economic evaluation of physician services and hospitals. Part of this must reflect that scientific evidence from clinical trials is available for drugs and new technologies as it is often a requirement of approval processes, and they may be more suitable for evaluation through a randomized clinical trial. In contrast, it must be the case that for a large proportion of physician and hospital services, there is no scientific evidence of effectiveness; hence there are no data to perform cost-effectiveness studies on a comprehensive basis. Unlike effectiveness studies where clinical trials can be used to demonstrate if there is a health benefit from an intervention - an objectively determined outcome - cost-effectiveness involves value judgments as to the relative worth of interventions that do not provide an obvious solution for decision-makers to defend their choices of core services. Delisting because of a high opportunity cost signifies that some patients are not worth the resources.

If physician services were to be delisted not because they are ineffective, but because they are effective but expensive, then would the public be comfortable with "medical reasonableness" as the operational definition of medical necessity, if governments can expect litigation over their rationing decisions? Flood et al. ${ }^{63}$ note that there is not universal acceptance of the costeffective criterion due to concerns over the methodology and the potential for disagreements over the value judgments of the relative importance of needs. ${ }^{64}$ For example, to address the concern that some needs are more urgent than others, Brouwer and Rutten ${ }^{65}$ describe the proposal for the Netherlands' funding decisions to have a threshold cost per Quality-AdjustedLife-Year (QALY) for cost-effectiveness that increases with the urgency of medical need to address a problem. Effectively, for a health intervention to be publicly funded, lesser needs must be judged as greater value for money than conditions with severe needs.

61 Similarly, evaluating the cost-effectiveness of new interventions as a consideration for public payment is not particularly problematic since it is not transparent whether payment for the new intervention represents a reallocation of spending from other services or treatments, or increased total health spending.

62 There is no a priori reason for limiting this exercise to just the health-care budget. A health intervention, even if it is more cost-effective than any other health intervention, may yield a considerably lower net benefit than, say, a poverty-reduction program or a new program for early-childhood education.

63 Flood et al., Defining the Medicare "Basket."

64 The authors describe decision-maker skepticism over the validity of economic modeling as a potential explanation for decision-maker reluctance to make wider use of economic evaluation of hospital and physician services. Deber ("Canada") highlights unresolved methodological issues of economic evaluation and health-technology assessment (HTA) more broadly as one reason for the limited application of these criteria in decision-making.

65 Brouwer and Rutten, "The Netherlands." 
Cost-effectiveness as a consideration for public payment has been applied in some health-care systems (the Netherlands, Oregon) and in Canada, outside of the medicare basket for drugs and new technologies. Shiell and Mooney ${ }^{66}$ assess that in the small number of cases where delisting decisions have factored in cost-effectiveness considerations, as in Oregon, the services that were delisted were few in number and not particularly important with respect to overall expenditures. Consequently cost savings were small. Flood et al.$^{67}$ highlight as well that the Oregon approach shows the political difficulty of implementing this sort of rationing scheme.

It is curious that health-economic studies of cost-effectiveness do not address whether costeffectiveness studies on a system-wide level would be good value for money in terms of reducing health-care spending. Cost-effectiveness studies performed at a system-wide level would require large expenditures ${ }^{68}$ While economic evaluation and health-technology assessments are feasible for evaluating new drugs, devices and treatments, they are not inexpensive. The scale on which these evaluations would need to be performed to assess all existing medicare and non-medicare services would seem to be enormous, particularly in comparison to the expected gains represented by cost-containment for the public payer.

\section{Ethical Issues}

A number of authors discuss the practical challenges of defining health-care coverage boundaries. Sabin and Daniels argue that "to be useful, a model for defining medical necessity must pass three tests: Does it make distinctions the public and clinicians regard as fair? Can it be administered in the real world? and, Does it lead to results that society can afford?" 69

For example, an important dimension of the equality value that informs our public medicare system concerns how to prioritize needs across Canadians. Neil Stuart and Jim Adams ${ }^{70}$ propose that public funding of medically necessary services be organized to reflect a "hierarchy of needs." They suggest thinking about medical necessity as a hierarchical continuum of services, rather than a binary construct of necessary or unnecessary. Their proposal is for a pyramid model, with the most basic needs (environment needs, such as air and water) forming the base, then higher levels progressing from basic health needs (immunization and prevention) to medically necessary (acute disease care), to health enhancement and finally, optimal health. The foundation of the pyramid represents items seen as societal rights, and the

66 Shiell and Mooney, "A Framework for Determining."

67 Flood et al., Defining the Medicare "Basket."

68 Interestingly, it is rare to see the costs of cost-effectiveness studies discussed. For example, David Hailey ("Health Technology Assessment in Canada: Diversity and Evolution," The Medical Journal of Australia 187, 5 (2007): 286-287) describes that, in Montreal, the McGill University Health Centre established a health-technology assessment (HTA) unit to provide advice on resource-allocation decisions. Recommendations from 16 reports were all incorporated into hospital policy, with estimated budget savings of about $\$ 3$ million per year. He also reports that a detailed study of the impact of 21 assessments in the Quebec health system found that all but three of the reports were found to have influenced policy, for a cost savings of between \$16 million and \$27 million per year. Hailey does not report the cost of producing the HTA advice, including the resource costs of producing scientific evidence to inform the decisions.

69 Sabin and Daniels, "Determining Medical Necessity," xx.

70 N. Stuart and J. Adams, "The Sustainability of Canada's Healthcare System: A Framework for Advancing the Debate," Longwoods Review 4, 4 (2007): 96-102. 
apex represents those services suited to market delivery. The challenge for a decision-maker in applying these criteria is that the boundaries between these categories are not particularly easy to establish nor do the authors propose how they might be.

An alternative conceptualization of the purpose of medicare could be to meet needs that arise from involuntary conditions. If someone has a health condition that could have been avoided with different choices and behaviours, then it could be considered just to not consider them as having equal claim to compensation for meeting that need. ${ }^{71}$ This particular notion of egalitarianism, which focuses on addressing inequalities arising from involuntary disadvantage, is not one that has been accommodated by the Canadian health-care system in its current state, nor was it seriously considered by the Romanow Commission's assessment of the moral superiority of the Canadian medicare system.

Michael $\mathrm{Yeo}^{72}$ discusses the problem of how, in a publicly funded health-care system, the healthy have to pay the health-care costs of those who willingly harm themselves, and that a lot of medical need is created through people making poor choices. In a similar vein Culyer and Wagstaff argue the following: ${ }^{73}$

"It is surely inconsistent to claim, on the one hand, that it is equitable for health differences to exist where they are the result of different choices made from the same choice set and, on the other, that people who damage their health through their own actions nonetheless have the same rights to health care as those who look after their health. One cannot, in other words, consistently maintain that it is equitable both that smokers have a lower health status than non-smokers and that they have the same rights as non-smokers to receiving treatment to restore their health when they fall ill."

But the challenge of distinguishing voluntary from involuntary disadvantage is not trivial. Yeo argues that we would need to determine the extent to which so-called lifestyle choices really are "choices," and to what extent are people victims of their own lifestyles. When choices result in people receiving health-care services in excess of others who are more responsible in efforts to maintain their health, Yeo and Carole Luckock ${ }^{74}$ propose that justice could be served by treating people unequally according to what they deserve. A health-care arrangement that provides access to health-care resources solely on the basis of need can place an undeserved burden on the responsible and an undeserved benefit to the irresponsible. It could be considered unfair that those who do use resources effectively should have to pay extra to compensate for those who are wasteful.

71 G.A. Cohen, "On the currency of egalitarian justice," Ethics 99 (1989) 906-944.

72 Michael Yeo, "Ethics and Economics in Health Care Resource Allocation," Queen's-University of Ottawa Economic Projects, Working Paper Series 93-07, 1993.

73 Culyer and Wagstaff, "Equity and equality in health and health care," 45.

74 M. Yeo and C. Luckock, "Quality v. equality: the divided court in Chaoulli v. Quebec," Health Law Journal 14 (2006) 129-150. 
Finally, with respect to the use of public payment for medically necessary services, should medical needs be considered contingent on a patient's ability to pay? That is, the need for public payment for a health need differs across the population and it is not obvious that a rich person's health needs should be considered equal to a poor person's health needs with respect to public payment for services. Bliss ${ }^{75}$ proposes that, as has been the case with other social programs in Canada, universality in health care can be maintained while we revisit the definition for the "universal entitlement" to full payment for necessary hospital and medical services. Here, Bliss seems to be proposing a return to using medical necessity as a criterion for a health-coverage floor:

\footnotetext{
"The simple, politically realistic, and philosophically important phrasing of the question is this: Why should government continue to pay for the healthcare of the well-to-do? Why should the state pay for the banker's coronary bypass, the retired hockey player's hip replacement, elbow reconstructions for the ladies who lunch? And so on. Does the state entitle everyone to all the healthcare they need, or does it entitle the economically needy to the benefits of modern healthcare?"76
}

Targeting scarce health-care dollars at Canadians with less ability to pay may be a more logical and effective use of public funds.

\section{PAYMENT REFORM TO ELIMINATE THE NEED TO DEFINE MEDICAL NECESSITY}

Blomquist ${ }^{77}$ believes efforts to rethink the boundaries of medical necessity are an example of a lower-priority reform. Reforms such as changing from fee-for-service to capitation payment in primary care should be a higher priority than changing the rules governing private payment for medicare services.

Charles et al. reinforce Blomquist's view. ${ }^{78}$ They argue that focusing on medical necessity locks Canadians into a policy framework of preserving the status quo. The authors view the need to assess medically necessary services as contingent on fee-for-service reimbursement systems that pay a fixed price for each service provided from a list of insured benefits.

Capitation-based payment, which is prospective payment for specified classes of care (e.g., primary care), does not tie payment to the cost of each service provided by an organization. Clinics, group practices and care networks can deliver care via teams of providers, not just physicians, creating opportunities for more cost-effective care through substitution of lesscostly providers for more-costly physician care, when such substitution is appropriate.

\footnotetext{
75 Bliss, "Critical Condition."

76 ibid, page 22.

77 Blomquist, "Reforming Canadian Medicare."

78 Charles et al., "The Role of Medical Necessity."
} 
Hospitals in Canada have been reliant on public funding for most of the medicare era, with global budgets that were not determined by the volume of services provided - as private physicians' budgets are, with retrospective fee-for-service payment. Deber ${ }^{79}$ notes that capping budgets on hospitals in the 1990s without impacting provider autonomy (local hospital boards) provided an opportunity and an incentive for cost-shifting nursing care, rehabilitation services and pharmaceuticals outside of the hospital setting into the non-medicare mixed-payment category of services. In other words, hospitals facing tighter budgets made decisions about what services or treatments needed to be part of their core activities and which could be left to other settings and sources of payment. A capitation-based payment for physicians could similarly incent physicians to consider similar forms of cost sharing, including to alternative providers who can substitute for physician services.

\section{SO, WHERE ARE WE?}

We indicated in our introduction to this paper that we would make no attempt to answer the question of what constitutes "medically necessary services." We understood that to be an easy promise to keep because, as we have tried to show in our discussion, no one knows what it means. We hope our discussion makes it equally clear that it may be impossible to ever come up with a definition that pleases every Canadian. The definition is tied up in personal circumstances, shifting understanding of what is affordable, concepts of fairness and equity, and different understandings of who is in the best position to make these choices.

But saying "it's hard" cannot be an acceptable excuse for policy-makers. All difficult questions of public policy demand decisions that differentially affect people depending on their personal circumstances, are constrained by what is affordable, and challenge concepts of what is fair. Failing to make this difficult decision with respect to publicly funded health care - arguably the most important public-expenditure program in Canada - represents a failure of public policy.

And it is a failure that has serious consequences. It is a failure that results in the wealthiest Canadian receiving annual physicals paid for by taxpayers, while the poorest Canadian is required to privately fund the rehabilitation costs required to recover from, or simply cope with, a traumatic brain injury. It is also a failure that has caused many Canadians to assume that coverage exists where, in fact, it does not and, so, has resulted in them not adequately preparing for catastrophic outcomes or even the simple and inevitable consequences of growing old.

We are not suggesting there is an easy answer; we know there is not. What we are suggesting is that a clear definition of what health services the publicly funded health-care system will pay for - and those it will not - must be made, however imperfect that decision will be.

79 Deber, "Canada." 


\section{GLOSSARY}

This glossary provides short definitions of certain terms used throughout our paper. It also provides a brief description of key reports and commissions dealing with issues relevant to the definition of medical necessity.

Canada Health Act (CHA): Federal legislation, passed in 1984, establishing criteria and conditions related to insured health services and extended health services that provincial and territorial governments must fulfill to receive the full federal cash contribution under the Canada Health Transfer. The aim of the CHA is to ensure that all eligible residents of Canada have reasonable access to insured services on a prepaid basis, without direct charges at the point of service. Insured health services are: hospital services, provided to inpatients or outpatients, if the services are medically necessary for the purpose of maintaining health, preventing disease or diagnosing or treating an injury, illness, or disability; and medically required physician services rendered by medical practitioners. (www.hc-sc.gc.ca)

Medicare: Publicly funded health care as defined by the 1957 Hospital Insurance and Diagnostic Services Act, the 1966 Medical Care Act and the 1984 Canada Health Act.

Single-payer coverage: One payer covers the full cost of a service.

First-payer coverage: In a multiple-payer setting, the first payer covers the first dollar and subsequent costs up to a ceiling, beyond which the second or higher-order payers cover the cost.

Universal first-dollar coverage: All people in the population have the first dollar of cost, and subsequent costs up to a ceiling, paid for.

Fee for service: Fixed-price reimbursement of services delivered.

Capitation payment: Prospective per-patient payment for services to be delivered over a defined time period.

Kirby Commission: Formally known as the Report of the Standing Senate Committee on Social Affairs, Science and Technology, but usually referred to by referencing the name of the chair of the committee, Senator Michael Kirby. The Commission is best known for recommendations to extend public payment for catastrophic prescription drug costs, and for offering a health-care "guarantee" that allow individuals access to services outside their province or country if wait times become excessive. The Kirby Commission released its recommendations in October 2002, just ahead of the release of the report of the Romanow Commission.

Romanow Commission: Formally known as the Commission on the Future of Health Care in Canada, but usually referred to by referencing the name of the chair of the Commission, Roy Romanow. The Commission released its final report in November 2002 and is best known for offering a strong defense of universal first-dollar coverage of health-care needs. 



\title{
ABOUT THE SCHOOL OF PUBLIC POLICY
}

The School of Public Policy will become the flagship school of its kind in Canada by providing a practical, global and focused perspective on public policy analysis and practice in areas of energy and environmental policy, international policy and economic and social policy that is unique in Canada.

The mission of The School of Public Policy is to strengthen Canada's public service, institutions and economic performance for the betterment of our families, communities and country. We do this by:

- Building capacity in Government through the formal training of public servants in degree and nondegree programs, giving the people charged with making public policy work for Canada the hands-on expertise to represent our vital interests both here and abroad;

- Improving Public Policy Discourse outside Government through executive and strategic assessment programs, building a stronger understanding of what makes public policy work for those outside of the public sector and helps everyday Canadians make informed decisions on the politics that will shape their futures;

- Providing a Global Perspective on Public Policy Research through international collaborations, education, and community outreach programs, bringing global best practices to bear on Canadian public policy, resulting in decisions that benefit all people for the long term, not a few people for the short term.

\author{
The School of Public Policy \\ University of Calgary, Downtown Campus \\ 906 8th Avenue S.W., 5th Floor \\ Calgary, Alberta T2P $1 \mathrm{H} 9$ \\ Phone: 4032107100
}

\section{DISTRIBUTION}

Our publications are available online at www.policyschool.ca.

\section{DISCLAIMER}

The opinions expressed in these publications are the authors' alone and therefore do not necessarily reflect the opinions of the supporters, staff, or boards of The School of Public Policy.

\section{COPYRIGHT}

Copyright ( $\odot 2013$ by The School of Public Policy.

All rights reserved. No part of this publication may be reproduced in any manner whatsoever without written permission except in the case of brief passages quoted in critical articles and reviews.

ISSN

1919-112x SPP Research Papers (Print) 1919-1138 SPP Research Papers (Online)

\section{DATE OF ISSUE}

October 2013

\section{MEDIA INQUIRIES AND INFORMATION}

For media inquiries, please contact Morten Paulsen at 403-453-0062.

Our web site, www.policyschool.ca, contains more information about The School's events, publications, and staff.

\section{DEVELOPMENT}

For information about contributing to The School of Public Policy, please contact Courtney Murphy by telephone at 403-210-7201 or by e-mail at cdmurphy@ucalgary.ca. 


\section{RECENT PUBLICATIONS BY THE SCHOOL OF PUBLIC POLICY}

\section{ENHANCING THE ALBERTA TAX ADVANTAGE WITH A HARMONIZED SALES TAX}

http:/ / policyschool.ucalgary.ca/ ?q=content/ enhancing-alberta-tax-advantage-harmonized-sales-tax

Philip Bazel and Jack M. Mintz | September 2013

\section{ACCOUNTABILITY BY DESIGN: MOVING PRIMARY CARE REFORM AHEAD IN ALBERTA}

http:/ / policyschool.ucalgary.ca/ ?q=content/accountability-design-moving-primary-care-reform-ahead-alberta Dr. Shannon M. Spenceley, Cheryl Andres, Janet Lapins, Dr. Robert Wedel, Dr. Tobias Gelber, L.M. Halma | September 2013

\section{WIRELESS COMPETITION IN CANADA: AN ASSESSMENT}

http:/ / policyschool.ucalgary.ca/?q=content/ wireless-competition-canada-assessment Jeffrey Church and Andrew Wilkins | September 2013

THE CANADIAN MANUFACTURING SECTOR, 2002-2008: WHY IS IT CALLED DUTCH DISEASE?

http:/ / policyschool.ucalgary.ca/?q=content/ canadian-manufacturing-sector-2002-2008-why-it-called-dutchdisease

Stephen Gordon | September 2013

REDISTRIBUTION OF INCOME: POLICY DIRECTIONS

http:/ / policyschool.ucalgary.ca/?q=content/redistribution-income-policy-directions James Davies | August 2013

INCOME INEQUALITY AND INCOME TAXATION IN CANADA: TRENDS IN THE CENSUS 1980-2005 http:/ / policyschool.ucalgary.ca/ ?q=content/income-inequality-and-income-taxation-canada-trends-census1980-2005

Kevin Milligan | August 2013

INCOME INEQUALITY, REDISTRIBUTION AND ECONOMIC GROWTH http:/ / policyschool.ucalgary.ca/?q=content/income-inequality-redistribution-and-economic-growth Bev Dahlby and Ergete Ferede | August 2013

DIPLOMACY, GLOBALIZATION AND HETEROPOLARITY: THE CHALLENGE OF ADAPTATION http:/ / policyschool.ucalgary.ca/?q=content/ diplomacy-globalization-and-heteropolarity-challenge-adaptation Daryl Copeland | August 2013

UNHEALTHY PRESSURE: HOW PHYSICIAN PAY DEMANDS PUT THE SQUEEZE ON PROVINCIAL HEALTH-CARE BUDGETS

http:/ / policyschool.ucalgary.ca/ ?q=content/ unhealthy-pressure-how-physician-pay-demands-put-squeezeprovincial-health-care-budgets

Hugh M. Grant and Jeremiah Hurley | July 2013

TRENDS, PEAKS, AND TROUGHS: NATIONAL AND REGIONAL EMPLOYMENT CYCLES IN CANADA http:/ / policyschool.ucalgary.ca/ ?q=content/trends-peaks-and-troughs-national-and-regional-employmentcycles-canada 